\title{
The Development of Instructional Leadership Scale of Elementary School Principals in Indonesia
}

\author{
Agung Purwa Widiyan, Saowanee Sirisooksilp and Pennee Kantavong Narot \\ Khon Kaen University, Khon Kaen, Thailand \\ https://orcid.org/0000-0002-5459-8007 \\ https:// orcid.org/0000-0002-0960-7365 \\ https://orcid.org/0000-0003-3797-4119
}

\begin{abstract}
This research aims to develop a scale to measure the practice of instructional leadership of elementary school principals in Indonesia. A sequential mixed-methods approach was chosen involving 238 school principals at public elementary schools in Bogor regency, Indonesia. The new instructional leadership scale showed appropriate levels of reliability and validity. The reliability of the developed scale was 0,875 . The construct validity was examined; second-ordered confirmatory factor analysis was at a satisfactory level, Chi-square $\chi^{2}=434.489$, CFI $=.934, \mathrm{p}=.113$, TLI $=.928$, RMSEA $=.019$, SRMR $=.046$. Convergent and discriminant validity were at an acceptable level as well. Qualitative results concluded that there were three identities of instructional leadership: instructional knowledge, attitude, and skills. By providing a new scale to measure instructional leadership roles, it could help navigate effectively that the roles of school leaders for learning reforms.
\end{abstract}

Keywords: Confirmatory Factor Analysis; Elementary School; Instructional Leadership; Mixed Methods; School Principal

\section{Introduction}

A learning process has become a crucial factor in influencing school outcomes. It articulated the ability of teachers to facilitate students, and it also described the effectiveness of the role of the school principals in leading the school. Once, the school can question what is learning? It will influence the results of other academic works within the school relatively. Thus, educational practices that happen in school might be exactly regarded as learning to learn. Biesta (2010) proposed that the nature of learning is not only to ask about 'what learning is', but it is more profoundly and related to the content (what is learned), its relationships (from whom it is learned), and purpose (why it is learned). 
Also, Biesta (2010) suggested that the language of learning refers to understanding something from someone for a particular reason. This new notion of learning involved a very personal purpose for learning to take place. This change asserts a different term of learning. Hence, the presence of someone to teach necessarily must be capable to exert the meaning of teaching into designing a learning environment or harnessing learning experience. Besides, this alluring reflection of learning and teaching has significantly changed the role of the school to become a learning community or space to learn. Therefore, this perception leads to changes in educative practices, and the implementation of instruction in the school has been shifted.

This shifting of instruction that occurred in the classroom should be led by a school leader who can create a shared sense of purpose in the school and nurture continuous instruction improvement. Those specific actions referred to a type of leadership role which promoted collaborative work purported to facilitate students' learning (Suratno, 2012). In this regard, the roles of school leaders relate directly to students' learning achievement and improvement (Elizabeth Dhuey \& Justin Smith, 2014). To unpack these progressive roles, a school leader requires a comprehensive understanding of the many facets and functions of instructional leadership.

Instructional leadership is defined as leadership roles that put teaching and learning processes in the school as a priority to enhance students' learning outcomes (Goldring, Preston, \& Huff, 2012; Nettles \& Herrington, 2007). As an instructional leader, a school leader is identified to notice instruction as an important component of feasible leadership practices (Murphy, 1990). Thus, one scale to infer these roles of instructional leadership well-known as the PIMRS (Principal Instructional Management Rating Scale) formulated by Hallinger, Wang, Chen, and Liare (2015).

The PIMRS highlights the importance of functions of principals on students' learning and other important outcomes. However, estimates of the PIMRS vary by type of contexts and different settings. It is, therefore, highly recommended to examine the additional scale to measure the roles of principals in different cultural contexts as the learning processes that occur in a diverse classroom environment as presented in many schools in Indonesia required distinct measurements. Jawas (2017), for instance, stated that school principals in Indonesia faced learning management issues where the learning process in daily practices was significantly influenced by sociocultural determination.

Besides, Jawas (2017) summarized that the roles of the school principals to understand the notion of learning culturally is needed. These consistent roles of leadership will enable the school principals to make necessary changes to certain conditions. To represent these new roles, another scale must be included, replaced, or substituted to identify the successful practices of instructional leadership.

This is not to argue for the effectiveness of new leadership scale development against PIMRS. Meanwhile, to cover certain phenomena in which school 
principals are important to perform their roles for particular reasons that establish positive effects on teacher's performance and desired student learning. Therefore, it is necessary to address that issue by changing the questions in the scale from a focus on the principal to a focus on collective practical effort.

A significant amount of research has shown increasing evidence that principals do influence student learning outcomes (Day, Gu, \& Sammons, 2016; Leithwood \& Day, 2008). Studies are elaborated to help inform a new approach to the curriculum preparation program for principals to ensure the efficacy of new principals to serve as effective instructional leaders (Hayes \& Irby, 2020; Vogel, 2018). Scholars have also measured the impact of cultural and organizational context on the practices of principal instructional leadership using the PIMRS (Ail, bin Taib, bt Jaafar, \& bin Omar, 2015; Day et al., 2016; Hallinger \& Hosseingholizadeh, 2020).

However, most of those scholars did not reach the essential dimension of instructional leadership for the specific characters of the sample or the issue. In this regard, the new scale assumes that PIMRS has deficit capability to measure as the change of the language of learning occurred within the school. For instance, Sofo, Fitzgerald, and Jawas (2012) concluded that socio-cultural factors of schools in basic education in Indonesia significantly influence the effectiveness of the learning process. Hence, additional scale or replacement is required to provide the school principals with standards that can navigate them in improving student learning opportunities and achievement.

Research on the efficacy of instructional leadership has confirmed that instructional leadership demonstrated by school principals influences what teachers do in the classroom and students' perceptions and experience of schooling (Hoy \& Hoy, 2006; Vogel, 2018). None of those research used the specific issue and context of the sample such as student learning reform. Understanding the specific issue and context by developing a new scale affects the analysis and understanding that is predicated in this research. Hence, this research believes that developing instructional leadership performed by principals can improve understanding of the learning reform concept applied in schools.

\section{Research Objectives}

The aims of this research were twofold; first, to examine the appropriate scale of the instructional leadership from the perspective of school principals in Indonesia. Second, to develop the instructional leadership scale that includes the perceptions of teachers and principals.

\section{Literature Reviews}

This section describes the concept of instructional leadership to identify a measurement model in the scale development process and to provide an overview concept in framing a new scale that can be used to conduct this research. 


\subsection{Instructional Leadership of School Principals}

Over the past decades, instructional leadership has been referred to as many proposed types. Based on literary works, the defining characteristics of instructional leadership can be summarized into two aspects. First, this research defined instructional leadership as the roles or actions of school leaders in leading schools, that is reflected in program activities, concerns in curriculum development, teaching and learning values, and qualification (DeVries, 2017; E Dhuey \& J Smith, 2014; Gawlik, 2018; Lochmiller \& Mancinelli, 2019; Mackey, 2016; Shaked, Glanz, \& Gross, 2018; Terosky, 2016; Wright, 2010; Zhou \& Li, 2015).

Second, instructional leadership is referred to as behaviors, beliefs, expectations, and visions of school principals towards the instruction process in leading schools (Ail et al., 2015; DeArmas, 2015; Hayes \& Irby, 2020; Lear, 2017; Simmons, 2019; Vogel, 2018). Both definitions above revealed common points that explain leading learning in the school as purposive actions. However, the leadership roles are formed by identifying learning objectives that are more different from the common instructional leadership. Therefore, school principals need specific roles to navigate the school to achieve its purposes.

The most cited definition of instructional leadership is the capabilities and abilities of school principals who lead the school by conducting the roles that are very concerned with exploring curriculum development, improving teachers' competencies, and creating a positive learning climate for the student (Hallinger, Wang, Chen, \& Liare, 2015). It is based on the patterns most scholars regard and reflect on goals, instruction, curriculum design, teaching and learning practices, and organizational structures (Krug, 1992). However, there is not a clear consensus about instructional leadership definitions and their dimensions. Even, some scholars argued that most instructional leadership constructs were formed by researcher perspectives more than considering the roles and actions to adjust the effectiveness of the learning process in the school.

Applying self-determination, this research modified the existing instructional leadership measurement models for suitability in the Indonesian context. It was inspired by several scholars, including, first, P. Hallinger and J. Murphy, P. Hallinger, W.-C. Wang, C. Chen, and D. Liare (Hallinger \& Murphy, 2013; Hallinger et al., 2015) proposed a widely used conceptual framework called the PIMRS with three dimensions: defining the school mission, managing the instructional program, and developing a positive school learning climate.

Second, Nettles and Herrington (2007) concluded seven consistent roles of school leadership that had direct effects on student achievement: monitoring school progress, building a shared mission and vision, creating a safe and orderly academic environment, involving stakeholders, focusing on instruction, setting high expectations for student performance and encouraging professional development.

Third, Blase and Blase (1999) encouraged instructional leadership beyond the observation process. This model of instructional leadership emphasized 
instructional coaching, professional development practices, and curricular development practices that follow the classroom observation. Fourth, Robinson (2011) suggested a five-dimensional framework for instructional leadership: (1) establishing goals and expectations; (2) strategic resourcing; (3) planning, coordinating, and evaluating teaching and the curriculum; (4) promoting and participating in teacher learning and development; and (5) ensuring an orderly and supportive environment. All dimensions depicted above are simplified into the new scales as the modified measurement model. Hence, the results of synthesizing all dimensions are necessary to figure out the potential appropriate dimensions for Indonesian basic education.

Thus, the measurement model of instructional leadership used in this research can be represented as a conceptual framework that covered five dimensions (see Figure 1). Firstly, defining missions is measured by the ability to decide the role and responsibility of all school's elements as the way to achieve the vision and the goals of the school (Ail et al., 2015; Avolio, 2007). Secondly, adopting an innovative curriculum is reflected by the role of the school principal to provide teachers with assistance and help for designing an innovative curriculum based on school needs and character (Day et al., 2016; Elizabeth Dhuey \& Justin Smith, 2014).

Thirdly, supplying professional development is displayed from the role of the school principal to prepare teachers and parents with the program that can upgrade their competencies to become more experienced teachers and educators (Bolman \& Deal, 2017; DeArmas, 2015). Fourthly, promoting a positive learning climate is referred to as the role of the school principal to provide teachers and students with the school environment including programs and facilities that are effectively helping them out to teach and learn (Badri, Amani-Saribaglou, Ahrari, Jahadi, \& Mahmoudi, 2014; Halverson, Grigg, Prichett, \& Thomas, 2007). Lastly, conducting supervision is specified by indicators of the role of the school principal to monitor teachers' performance and students' work by indicating the needs and obstacles (Brazer \& Bauer, 2013; DeVries, 2017; Glickman, Gordon, \& Ross-Gordon, 2014).

\subsection{The Relevance of Instructional Leadership for Learning Improvement in Indonesian Schools}

The primary purpose of educational leadership has been regarded as the most priority of the students' adaptive learning which is reflected by accumulating empirical evidence (Davies, 2005; Leithwood \& Jantzi, 2005; Southworth, 2005). Moreover, the presence of effective school leadership for school improvement is necessary as it facilitates teachers and students with encouragement, appropriate classroom activities, school culture, and organizational direction. All of which affect successful teaching and adaptive learning that significantly influence student outcomes are essential (Pitsoe \& Letseka, 2013; Seashore Louis, Dretzke, \& Wahlstrom, 2010; Sergiovanni, 2015).

Hence, instructional leadership as the main core of leading learning emphasizes a new conception of creating accountable learning systems in schools. It has 
underlined the mutual effect of teacher empowerment and students' learning purpose.

In the context of Indonesian schools, the school principal is equipped with several competencies to be qualified as a school leader. These competencies including personality, management, entrepreneurship, supervision, and social, are formulated and disclosed in the Regulation of the Ministry of Indonesian National Education 2007 (Silalahi \& Yuwono, 2018). This law introduces the competencies that potentially can navigate the practices of principals' leadership towards school reforms.

However, to achieve school reform goals effectively, competencies are not sufficient for the school principal to manage educational work in the school reforms. School principals also require a type of leadership that can enable them to demonstrate actions and practices of accountable learning processes significantly and be responsible for building strong teams of teachers to accommodate students' needs adequately and lead in improving student outcomes.

In other words, school reform in the Indonesian educational context is quite specific and different. It was defined as a shift of pedagogical approaches between teacher and students' instruction from traditional methods into reflective interaction with a particular purpose that intends to provide more opportunities for students' desires and needs (Jawas, 2017; Sofo, Fitzgerald, \& Jawas, 2012). It was clear for the objective of educational reforms must occur.

Therefore, the presence of a school principal who understands the impact of instructional leadership that can help the school principal build the teachers' capabilities and abilities to sustain instructional improvements is necessary (Honig, Copland, Rainey, Lorton, \& Newton, 2010). Likewise, the characteristics of principals' competence were mainly contained in the instructional leadership dimension.

To sum up, this research argues that developing a new scale of instructional leadership can bring enhancement of the practices of significant instructional improvement in schools.

\section{Research Method}

This research was approached by using a sequential mixed method (Kroll \& Neri, 2009). It is typically characterized by an initial quantitative phase, which is then followed by a qualitative data collection phase. Findings from the qualitative study component are used to explain and contextualize the results from the quantitative study component (Kroll \& Neri, 2009).

This explanatory sequential mixed method has been widely utilized by many empirical studies in the educational setting for developing scale (Yin, 2017). Therefore, this research was divided into two phases; the first phase was quantitative research to focus on the concept discovery of local perceptions and practices of instructional leadership in Indonesian schools and calculate the degree of importance on instructional leadership from survey exploration of 
school principals. The second phase was research development that included collecting qualitative data from teachers, and school principals to integrate the relevance of the findings with the sample.

\section{Phase 1 Quantitative Research}

\subsection{Measures}

A survey was applied with questionnaire items using the result of synthesizing several theories related to the literature of instructional leadership in closedended questions. The questions were constructed in the form of a checklist and Likert-type questions. Checklist items asked the demographic characteristics of the respondents. Likert-type questions measured the current frequency of identified instructional leadership practices. The scale format was designed using a five-point rating scale of lowest $=1, \mathrm{low}=2$, neither low nor high=3, high $=4$, and highest $=5$. In summary, the proposed instructional leadership scale consists of 25 indicators with 5 items in each of five dimensions: defining mission, adopting curriculum, supplying professional development, promoting a positive learning climate, and conducting supervision.

This survey was conducted on the internet-based method. The period of the survey process was approached from March 20 to May 10, 2020. This research is impartial and independent; the responses from respondents were protected by not revealing their answers in the research findings.

However, there is a key limitation that restricts this research. Although this research applied quantitative procedure during the covid-19 pandemic, the quantitative findings were done promptly well. The increase of online learning across the archipelago (Rahiem, 2020) would practically ease the procedure of quantitative data collection and at the same time would keep research data at a manageable level.

A representative framework of instructional leadership scale that is appropriate to the context of Indonesia was needed. There were three experts from Indonesia and two experts from Thailand involved as they had over five-year experience in the educational leadership field. They were interviewed to help build the item of question and get a better understanding of the predictors towards the content quality of the instructional leadership scale.

Before distribution, a pilot-test was conducted to measure the validity and reliability. The validity of the questionnaires was established by examining their content validity through experts' judgment. Content validity was evaluated based on the criteria of the extent to which statements or questions represent the issue, and they are supposed to measure the quality and feasibility, considered by the experts in the field (Kumar, 2005).

Besides, to measure the reliability, a questionnaire trial was applied to independent groups of school principals. The questionnaires were distributed through the Internet using google form. The groups were contacted through their social media network before the delivery of the questionnaire for asking their agreement to participate. SPSS Statistics 26 software was used to export the 
data, and Cronbach's Coefficient Alpha was calculated to measure the reliability of all variables. The result of Cronbach's Coefficient Alpha for this principal questionnaire was 0.875 . This means that the questionnaire was reliable.

\subsection{Population and Sample}

A purposive sampling technique was used to select the 238 from the 588 elementary school principals. All school principals involved were currently leading elementary public schools located in Bogor regency. The school that has a high national examination score and a medium level of accreditation of school is determined as the criteria for choosing the sample. To get the number of samples, the Taro Yamane formula was employed to calculate the sample' size.

\subsection{Data Analysis}

The construct validity of the scale was assessed in two approaches in this research. First, confirmatory factor analysis (CFA) was used to examine the factorial validity of the scale. The measurement model was also assessed through model fit by Chi-square test $\chi^{2}$ and four other models fit indices: the Comparative Fit Index (CFI), the Tucker Lewis index (TLI), the Root MeanSquare Error of Approximation (RMSEA), and the Standardized Root MeanSquare Residual (SRMR). The thresholds of mentioned indices for satisfactory fit suggested by R. Kline (Kline, 2016): p-value of Chisquare's test $>0.05, \mathrm{CFI}>0.95$, TLI $>0.95$, RMSEA $<0.08$, SRMR $<0.08$. Second, convergent and discriminant validity were calculated. R. Kline, (Kline, 2016) suggested that the value of intercorrelations among variables is considered convergent and discriminant validity. For convergence validity, this research measured two particular items: (1) Composite reliability (CR); and (2) average variance extracted (AVE). In general, the value of composite reliability is more than 0.6 indicating that the inherent consistency of all measurement questions is higher. The value of the average variance extracted (AVE) is greater than 0.5 indicating that the measurement questions can better represent the characteristics of each research variable in the model (Carbrera-Nguyen, 2010). For discriminant validity, the analysis can be performed by examining the square root of the AVE value. When the square root of the mean-variance extraction rate of each measurement question is higher than the correlation coefficient between the variables, it indicates that there is a strong discriminant coefficient between the variables (Brown, 2015). Thus, the discriminant validity of latent factor correlation among most of the constructs has been verified to meet standards (Shaffer, DeGeest, \& Li, 2016).

\section{Phase 2 Qualitative Research}

\subsection{Informants}

All informants were purposely selected from the schools that met the given criteria with different contexts, types, locations, and sizes in Bogor, Indonesia. However, teachers and school principals in this step have an adequate strategic character for research to develop the scales (Patton, 2002). In summary, six schools were included in this research. The informants in this research on the meaning of instructional leadership included teacher representatives $(n=3)$ and school principals $(n=3)$. This research also considered some categories of the 
informants' expertise such as teaching experience, leadership experience, as well as willingness to be interviewed.

\subsection{Procedures and data analysis}

The interview method was utilized in this research. A semi-structured interview was used for qualitative data collection. The instrument consisted of the items based on the conceptual framework of the instructional leaders proposed by several scholars (Blase \& Blase, 1999; Hallinger et al., 2015; Krug, 1992; Robinson, 2011). For each construct to develop instructional leadership, the interview questions were produced based on dimensions of instructional leadership included defining missions, adopting innovative curriculum, supplying professional development, promoting a positive learning climate, and conducting supervision. The final interview instrument comprises 15 main questions. Data collection was carried out using multiple methods because this research was unable to conduct direct interviews due to the large-scale social restrictions that were in place during the research period, data collection, therefore, was completed by using the Google Meet application. The interview process was organized from June 15, 2020, to June 29, 2020. All informants were informed through a consent form before joining the interview. This research did not reveal the identities of all informants and did not report their personal information in the study findings.

In analyzing the data, transcription, coding, and thematic analysis were used in this phase to develop the main categories regarding the roles of instructional leadership. The research had identified subcategories, patterns, and relationships among codes and summarized them into categories within the data (Saldaña, 2016). In practice, the data was transcripted individually. After that, the data and detailed data were transformed into a code. The primary aim of coding was to establish a sense of categorical, conceptual, and theoretical structure. Codes were clustered to form new codes that led to the identification of themes. Finally, reviewing the categories to ensure the data appropriateness and feasibility and choosing the final types to design items for the instructional leadership scale were conducted.

\section{Research Result}

The results are presented in two main parts; the first part addresses the result of confirmatory factor analysis to assess the factorial construct of instructional leadership and respectively reported evidence of convergent and discriminant validity. The final part explains the impact of analyzing the categories of instructional leadership to generate the indicators.

\subsection{Instructional Leadership constructs}

Based on the analysis and synthesis results of literature on instructional leadership involving seven lecturers who are experts in the area of educational administration, they have validated the contents regarding their opinion towards instructional leadership development (Güngör, 2018). The results showed that the information that provided insights from the possible effects of synthesizing became the items to measure the roles of instructional leadership 
for further research. In summary, the developed instructional leadership scale, therefore, consisted of 25 indicators with a five-point rating scale questionnaire.

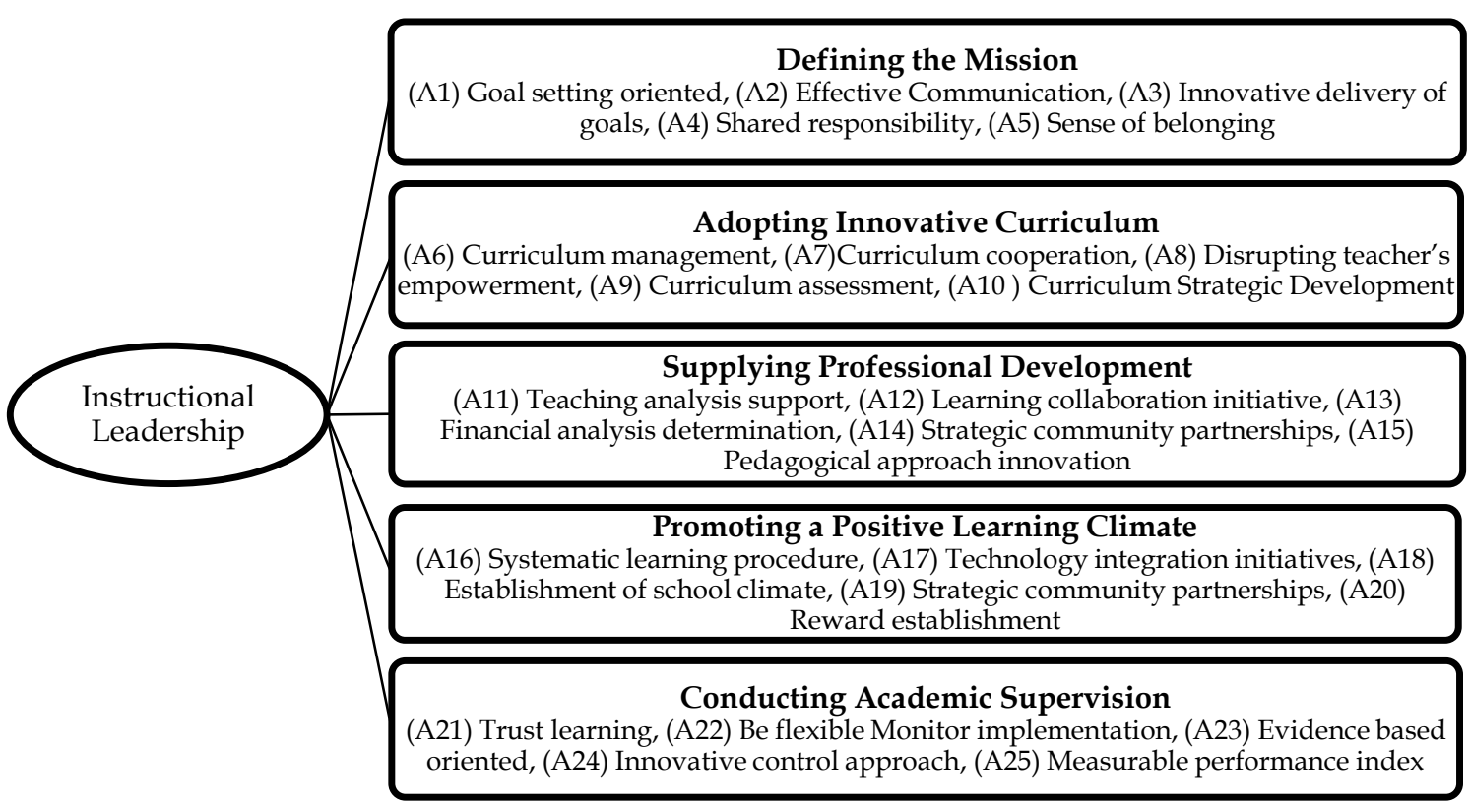

Figure 1. Dimensions of instructional leadership for the Indonesian education context

\subsection{Construct Validity: Confirmatory Factor Analysis}

The factorial validity, second-ordered confirmatory factor analysis (CFA) was examined as a part of construct validity. The result revealed the measurement model provided a good fit to the empirical data, $\chi^{2}=434.489, C F I=.934, p=.113$, $\mathrm{TLI}=.928$, RMSEA $=.019$, SRMR=.046. As seen in Figure 2, all standardized factor loading of both first and second-ordered construct were statistically significant and reasonably robust with factor loadings ranging from .73 to .94 for observed variables, as well as going from .57 to .98 for latent factors. Furthermore, the variance of all subscale scores was explained by Instructional leadership constructs with $\mathrm{R}^{2}$ ranging from .46 to .89 , and the variance of all observed variables was explained by each of the instructional leadership dimensions with $\mathrm{R}^{2}$ ranging from .51 to .95 . However, the five proposed dimensions of the instructional leadership model concluded adequate to confirm the instructional leadership construct. 


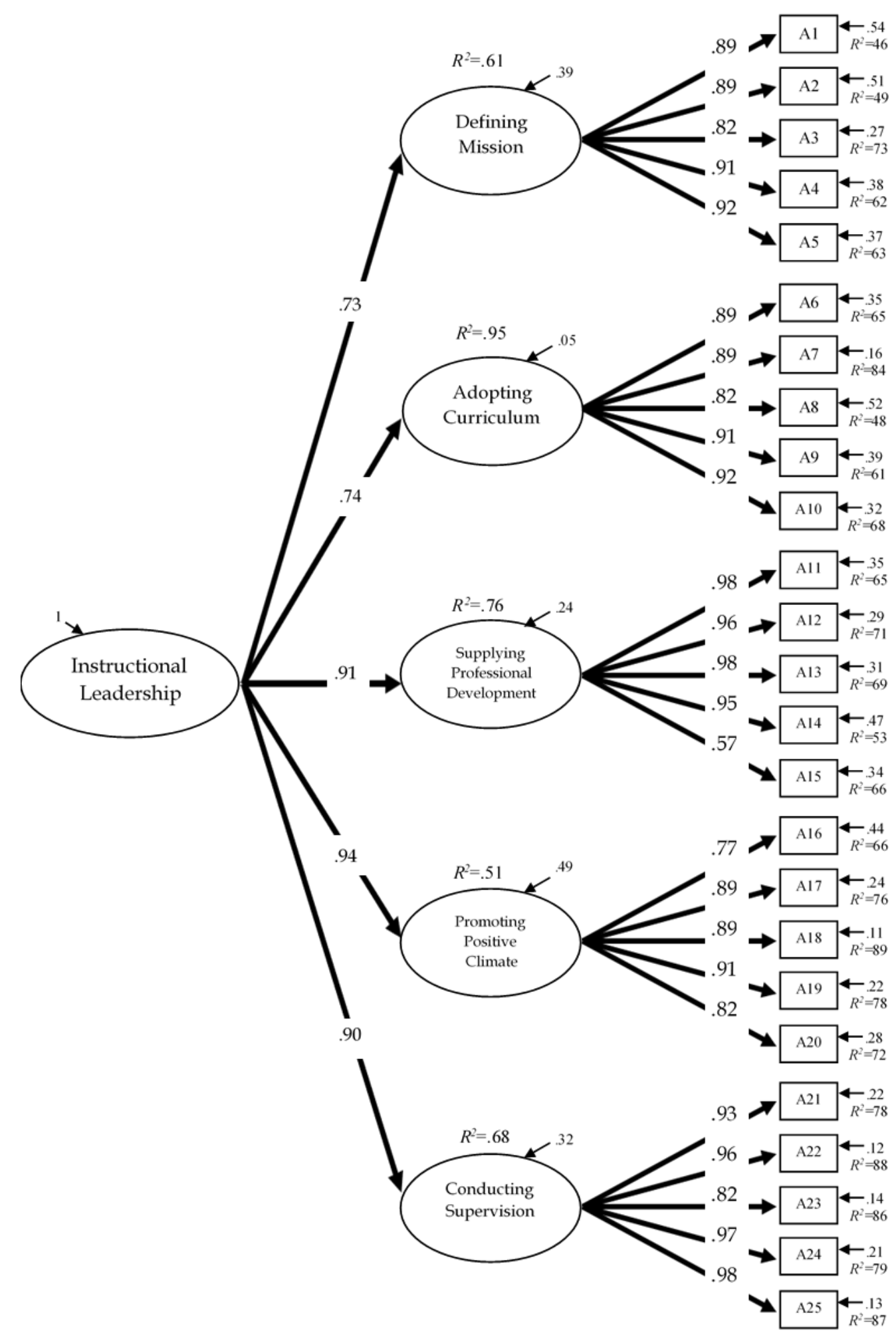

Figure 2. Second-ordered confirmatory factor analysis for the practice of instructional leadership

\subsection{Construct Validity: Convergent and Discriminant Validity}

Convergent validity was examined by calculating loadings of all the indicators; average extracted variance (AVE), composite reliability (CR), and discriminant validity should be examined by measuring whether AVEs are higher than the 
inner construct correlations. As shown in figure 2, the loadings of all the indicators are above 0.7, indicating that the observed variables have high convergent validity. Furthermore, there is a high correlation between the observed variables and the latent variables. As can be seen in table 1, the calculation of composite reliability is above 0.7 for all the variables, which means that the scale has achieved good reliability and average variance extracted (AVE) is more significant than 0.5 which indicates that the reliability of this model is good (Shaffer et al., 2016) and implies that the latent factors have an ideal convergence ability. Additionally, the square root of the mean-variance extraction rate of each measurement question shown in table 1 is greater than the correlation coefficient among the variables, which indicates that the difference between each measurement variable is better (Hair, Black, Babin, Anderson, \& Tatham, 1998). Thus, the discriminant validity of latent factors has verified a satisfactory level of discriminant validity. Therefore, from these results; it can be concluded that the developed instructional leadership scale has an acceptable level of both convergent and discriminant validity.

Table 1. Validity analysis of Instructional Leadership

\begin{tabular}{|c|c|c|c|c|c|c|c|}
\hline Construct Items & $\begin{array}{l}\text { Composite } \\
\text { Reliability }\end{array}$ & $\mathrm{AVE}^{1}$ & $\mathrm{DM}$ & $\mathrm{AC}$ & $\mathrm{SP}$ & PL & CS \\
\hline Defining Mission (DM) & 0.94 & 0.71 & 0.84 & & & & \\
\hline Adopting Curriculum (AC) & 0.83 & 0.59 & 0.53 & 0.77 & & & \\
\hline $\begin{array}{l}\text { Supplying Professional } \\
\text { Development (SP) }\end{array}$ & 0.93 & 0.69 & 0.67 & 0.65 & 0.83 & & \\
\hline $\begin{array}{l}\text { Promoting Positive Climate } \\
\text { (PL) }\end{array}$ & 0.93 & 0.70 & 0.77 & 0.71 & 0.75 & 0.84 & \\
\hline $\begin{array}{l}\text { Conducting Supervision } \\
\text { (CS) }\end{array}$ & 0.96 & 0.75 & 0.62 & 0.62 & 0.65 & 0.62 & 0.86 \\
\hline
\end{tabular}

Note. AVE stands for average variance extract. * The bold numbers above are the square root of AVE. The bold numbers listed diagonally are the square root of the variance shared between the constructs and their measures. The off-diagonal variables are the correlations among the constructs. For discriminate validity, the diagonal variables should be larger than the off-diagonal variables.

\subsection{Qualitative Result}

Based on qualitative data analysis, this research summarized that the final instructional leadership scale fell into three overarching categories, each with related items of instructional leadership. The three identified themes are: (a) knowledge, (b) attitude, and (c) practice/skills

This research utilized 25 indicators of instructional leadership (as shown in figure 1 above) to be grouped into three groups, including knowledge, attitude, and practice/skills. This research concluded that as an instructional leader, school principals understand the ideas of instruction, the importance of teaching quality, and their roles in influencing teachers' performance as well as students' outcomes. The following is an illustration of the codification result. 


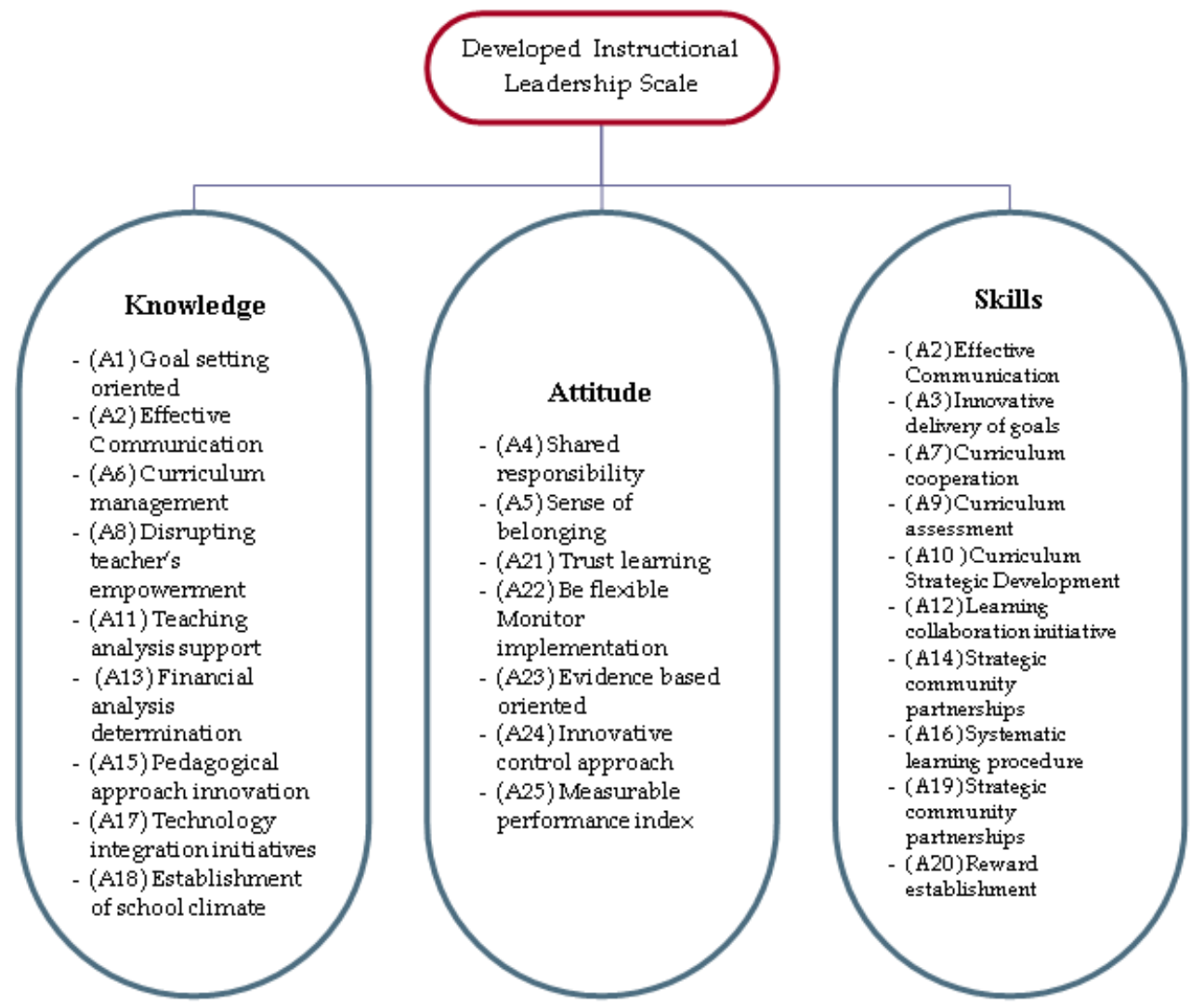

Figure 3. The result of codification

As can be seen in figure 3, it shows items of instructional leadership are mostly grouped into knowledge, attitude, and skills. This research grouped those items based on their similar meaning in categories. The notion of categories was inspired by Kraiger, Ford, and Salas (1993) who emphasized that development is started from knowledge, attitude, and skills. Hence, based on the result of data categorization, this research discovered that instructional leadership skills were the most concerned category of instructional leadership with 10 items, followed by knowledge ( 9 items), and attitude ( 7 items).

However, there was an interesting report in which effective communication was placed into two categories between knowledge and skills. This discovery navigated this research to explore the perspectives and insights about the relationship between knowledge, attitude, and skills of instructional leadership.

School principals who can communicate the reason for learning and instruction indicate a knowledgeable school principal as an instructional leader. A voice from the teacher explaining.

"Looking at the roles of a school principal who has played a very good job of taking things into the school's vision implementation and explaining it in a way that we are then aware of it. We appreciated to the school principal who knows how to relate to the teachers and understand how to enhance teachers' responsibility on school development" (DA) 
School principals are expected to be the leader of every student in school. To be an effective leader, a school principal must understand and require a broad improvement of skills and have a high level of confidence once spreading the vision and missions.

"In my view, as students learn with teachers and school principals need to understand that teaching and learning process in the classroom is very crucial for each of us. We cannot let students grow without we know their expression toward teachers and schools. Therefore, we try to provide stakeholders, parents, and the community with the agenda that we are planning to do, share, and open classroom processes. School principals are aware of the need for other participants to get involved as the way to increase the sense of belonging toward the school" (AM)

As can be seen from the statement above, the concern of instructional leadership is to achieve a high degree of instruction, and this process requires an understanding of the situation and asks the school principals to divide identity in two ways. First, inside identity, and second, outside identity. These identities included the items of instructional leadership to be replaced into specific for the particular purposes of leading instruction.

Instructional leaders navigated school principals to understand how to work collaboratively with teachers. This role of instruction requires awareness among the subjects of school. The school principal has figured out one role to be conducted.

"I am so appreciated once teachers are accepting my ideas. I have tried suggesting them in a way they can understand. The previous one was very hard for me to ask teachers to do what I recommended. However, since I kept my commitment to learning purpose and decreasing my intention while I experienced what teachers did, and I contributed what teachers have designed. After several trials, they give me fruitful endeavors" (AA)

Other respondents, however, felt that all roles of instructional leadership must be supported by the attitude that school principals need to show. This attitude becomes the capital to play the roles of the instructional leader as stipulated by this teacher.

"What makes me surprised is that the presence of our school principal in many activities including classroom management was so fully responsible as it seems to me it tells that "I am doing what I am saying". She took a dominant role when we discussed why students are happy to learn. She was committing to making sure that the process of learning in our school comprehensively run very well. We are not forced to do 'teaching' as we thought before. Moreover, teaching is referred to be so meaningful activity that we have never felt before. And this is because of our school principal. This awareness has been inspired by our school leader" (W)

\section{Discussion}

The results revealed that the developed instructional leadership scale showed adequate indicators both in reliability and validity. As for the validity of the scale, the CFA results provided evidence deemed to confirm that five constructs of instructional leadership capitalized by several scholars (Blase \& Blase, 1999; Hallinger et al., 2015; Krug, 1992; Robinson, 2011; Stronge, Ward, \& Grant, 2011) 
were suitable for Indonesian context. This evidence also indicates that the scale is appropriate for assessing the practice of Instructional leadership.

Some results pointed out that some constructs of instructional leadership have a lower value of $\mathrm{R}^{2}$ when compared to other constructs. It can be explained that its indicators included unclear descriptions within similar questions, it was a double perspective presented and was not relevant to their mindset and culture, which implied those items might increase error variance within the measurement results (Shaffer et al., 2016). Nevertheless, the convergent validity result was a reasonable level with a high correlation between both the latent factor and the observed variable score. The results can also explain why discriminant validity is accurate. Since this research has found a high correlation among constructs, it could be assumed that all constructs were measured by the same high-level factor. However, the explanation of this research with this issue is based on the authors' viewpoint regarding the notion of instructional leadership variables developed from the literature. The results of this research provide practical implications for further research to utilize a well-developed scale for measuring and determining the development of leadership.

This research also tried to conceptualize a model for preparing principals for instructional leadership. In the Indonesian context, aspiring principals must do on-the-job training admitting as a candidate before starting as a school principal. Unfortunately, aspiring principals were not also well-prepared for instructional leadership (Sofo et al., 2012), as the challenges that aspiring principals will face forward would be different from the challenge they get during in-service training. Hence, the developed instructional leadership model is needed in a leading school in this advanced era. As the research conducted by Brazer and Bauer (2013) which formulated a blended leadership, organizational theories, and managerial tools, as well as pedagogical knowledge, to create a model for enabling aspiring principal to become an instructional leader.

Hence, the results of this research proposed a developed instructional leadership scale to inspire the principal preparation program to focus more on instructional leadership. The essential dimensions of an effective principal as the leader can be reflected from the roles and the actions of the school principal as instructional leaders (Nixon, Packard, \& Dam, 2013). This is important since the understanding of how students learn, recognizing effective instructional strategies, and classroom management techniques that focused on diverse student learners will enable school leaders to transform school effectively (Zepeda, 2014).

In this research, instructional leadership is forwarded to be distinguished into three categories for the reason of development that is appropriate to the school principal competence and Indonesian context. The first category was knowledge which means that the instructional leadership model used is based on the information occurring in school and utilizes it by giving an appropriate response. For instance, this research indicated the item of goal setting oriented as knowledge is articulated whether or not the school principal realizes and understands the goal of learning and the purpose of teaching. This item needs 
school principals to demonstrate their knowledge by exploring the notion of their goal that they wanted to achieve. It is also related to the research conducted by Mackey (2016) who concluded that every role of school principal needs to be focused on students' achievement in which school principals understand where their students are, what the things that students want to be, and how to achieve it.

In Indonesia, socio-culture has been dominant as a factor that influences how school principal behaves, and it is in line with the result of research by Jawas (2017) which stated that trust learning is defined as an attitude indicating that school principal must pay attention to the condition and psychology of their teachers and students. To build a relationship that can be started by showing high integrity to the others, the school principal has an opportunity to ensure their teachers and students to trust by making a decision that is entirely for learning concern.

To play the roles of instructional leadership, a school principal is responsible for the quality of instruction in every classroom. This attention stimulates school principals to be capable and having the ability to at least solve the challenges that school faced by the creative mind and specific ability. Therefore, the presence of an instructional leader who can demonstrate strategic efforts to provide students with appropriate and meaningful learning and transform the school into a conducive place to learn is essential. This idea is agreed upon by a result of research conducted by Honig, Copland, Rainey, Lorton, \& Newton (2010) which addressed teaching and learning improvement requires top-down movement which school principals actively performed.

\section{Conclusion}

The result indicated that the instructional leadership scale developed in this research is a five-point rating scale. The scale can be measured by five dimensions including defining mission, adopting curriculum, supplying professional development, promoting a positive learning climate, and conducting supervision. This scale also showed a satisfactory level, both validity and reliability. Whoever may be involved can achieve this scale to measure the practice of instructional leadership to show informed evidence of their school to enhance instruction. Since the newly instructional leadership scale is developed based on the results of synthesizing theories; the results from the measurement process can therefore provide insightful information regarding the nature of instructional leadership that has been widely defined and elaborated. To assess the practice of instructional leadership precisely based on the proposed measurement model that is adequate to the context of elementary school principals requires the scale that can represent the effects of instructional leader. Besides, there was an identity shift for a school principal to play the roles of instructional leader. The school principal must be able to understand three categories included knowledge, attitude, and skills. This awareness towards categories helps school principal to measure their performance as an instructional leader. 


\section{Acknowledgments}

The authors acknowledge the Educational Administration Experts for content validity and thank Khon Kaen University as this research was supported by the Khon Kaen University Scholarship for ASEAN and GMS Countries Personnel Academic Year 2017. This research article was also a part of the dissertation. This research was ethically approved by the Khon Kaen University Ethics Committee in Human Research on March 19, 2020, with Reference No. HE633042. Written informed consent was obtained from all of the participants.

\section{Conflicts of Interest}

The authors declare no conflict of interest in the design of this research; in the collection, analysis, or interpretation of data; in the writing of the manuscript, or in the decision to publish the results.

\section{References}

Ail, N. M. B. M., bin Taib, M. R., bt Jaafar, H., \& bin Omar, M. N. (2015). Principals' instructional leadership and teachers' commitment in three Mara Junior Science Colleges (Mjsc) in Pahang, Malaysia. Procedia-Social and Behavioral Sciences, 191, 1848-1853. doi:10.1016/j.sbspro.2015.04.512

Avolio, B. J. (2007). Promoting more integrative strategies for leadership theory-building. American psychologist, 62(1), 25.

Badri, R., Amani-Saribaglou, J., Ahrari, G., Jahadi, N., \& Mahmoudi, H. (2014). School culture, basic psychological needs, intrinsic motivation and academic achievement: Testing a casual model. Mathematics Education Trends and Research, 4, 1-13.

Biesta, G. J. (2010). Why 'what works' still won't work: From evidence-based education to value-based education. Studies in philosophy and education, 29(5), 491-503. doi:10.1007/s11217-010-9191-x

Blase, J., \& Blase, J. (1999). Principals' instructional leadership and teacher development: Teachers' perspectives. Educational administration quarterly, 35(3), 349-378. doi:10.1177/0013161X99353003

Bolman, L. G., \& Deal, T. E. (2017). Reframing organizations: Artistry, choice, and leadership: John Wiley \& Sons.

Brazer, S. D., \& Bauer, S. C. (2013). Preparing instructional leaders: A model. Educational administration quarterly, 49(4), 645-684.

Brown, T. A. (2015). Confirmatory factor analysis for applied research: Guilford publications.

Carbrera-Nguyen, P. (2010). Author guidelines for reporting scale development and validation results. Journal of the Society for Social Work and Research, 1(2), 99-103. doi:10.5243/jsswr.2010.8

Davies, B. (2005). The essentials of school leadership: Paul Chapman Educational Publishing.

Day, C., Gu, Q., \& Sammons, P. (2016). The Impact of Leadership on Student Outcomes: How Successful School Leaders Use Transformational and Instructional Strategies to Make a Difference. Educational administration quarterly, 52(2), 221258. doi:10.1177/0013161×15616863

DeArmas, I. (2015). A Phenomenological Investigation of Professional Development and the Impact on Elementary Principals Instructional Leadership.

DeVries, R. (2017). The instructional leadership practices of elementary principals of average needs/resource capacity school districts in New York State: Sage Graduate School. 
Dhuey, E., \& Smith, J. (2014). How effective are school principals in the production of school achievement. Canadian Journal of Economics, 47(2), 634-663. doi:10.1111/caje.12086

Dhuey, E., \& Smith, J. (2014). How important are school principals in the production of student achievement? Canadian Journal of Economics/Revue canadienne d'économique, 47(2), 634-663. doi:10.1111/caje.12086

Gawlik, M. (2018). Instructional leadership and the charter school principal. School Leadership \& Management, 38(5), 539-565. doi:10.1080/13632434.2018.1439467

Glickman, C., Gordon, S., \& Ross-Gordon, J. (2014). SuperVision and instructional leadership: A developmental approach. In: Upper Saddle River, NJ: Pearson.

Goldring, E. B., Preston, C., \& Huff, J. (2012). Conceptualizing and Evaluating Professional Development for School Leaders. Planning \& Changing, 43.

Güngör, S. K. (2018). Content Analysis of Theses and Articles on Ethical Leadership. International Journal of Instruction, 11(4), 901-920. doi:10.12973/iji.2018.11457a

Hallinger, P., \& Hosseingholizadeh, R. (2020). Exploring instructional leadership in Iran: A mixed methods study of high-and low-performing principals. Educational Management Administration \& Leadership, 48(4), 595-616.

Hallinger, P., \& Murphy, J. F. (2013). Running on empty? Finding the time and capacity to lead learning. NASSP Bulletin, 97(1), 5-21. doi:10.1177/0192636512469288

Hallinger, P., Wang, W.-C., Chen, C., \& Liare, D. (2015). Assessing instructional leadership with the principal instructional management rating scale: Springer.

Halverson, R., Grigg, J., Prichett, R., \& Thomas, C. (2007). The new instructional leadership: Creating data-driven instructional systems in school. Journal of School Leadership, 17(2), 159-194. doi:10.1177/105268460701700202

Hayes, S. D., \& Irby, B. J. (2020). Challenges in preparing aspiring principals for instructional leadership: voices from the field. International journal of leadership in education, 23(2), 131-151. doi:10.1080/13603124.2018.1562102

Honig, M. I., Copland, M. A., Rainey, L., Lorton, J. A., \& Newton, M. (2010). Central office transformation for district-wide teaching and learning improvement. Center for the Study of Teaching and Policy, Seattle, WA.

Hoy, A. W., \& Hoy, W. K. (2006). Instructional leadership: A research-based guide to learning in schools: Pearson Education New Zealand.

Jawas, U. (2017). The influence of socio-cultural factors on leadership practices for instructional improvement in Indonesian schools. School Leadership $\mathcal{E}$ Management, 37(5), 500-519. doi:10.1080/13632434.2017.1366440

Kline, R. (2016). Principles and practice of structural equation modeling. New York: The ebook. In: THE GUILFORD PRESS.

Kraiger, K., Ford, J. K., \& Salas, E. (1993). Application of cognitive, skill-based, and affective theories of learning outcomes to new methods of training evaluation. Journal of applied psychology, 78(2), 311. doi:10.1037/0021-9010.78.2.311

Kroll, T., \& Neri, M. (2009). Designs for mixed methods research. Mixed methods research for nursing and the health sciences, 31.

Krug, S. E. (1992). Instructional leadership: A constructivist perspective. Educational administration quarterly, 28(3), 430-443. doi:10.1177/0013161X92028003012

Kumar, R. (2005). Research methodology: as step-by-step guide for beginners 2nd edition ed. NSW, Australia.: Pearson Education Australia. doi:10.1016/j.nepr.2011.11.008

Lear, J. C. (2017). An Examination of How and Why Teachers Participate in Instructional Leadership. East Stroudsburg University, Retrieved from http://jeffreylear.com/professional/lear_12_2017_dissertationCopy.pdf 
Leithwood, K., \& Day, C. (2008). The impact of school leadership on pupil outcomes. In: Taylor \& Francis.

Leithwood, K., \& Jantzi, D. (2005). A review of transformational school leadership research 1996-2005. Leadership and policy in schools, 4(3), 177-199. doi:10.1080/15700760500244769

Lochmiller, C. R., \& Mancinelli, J. L. (2019). Principals' instructional leadership under statewide teacher evaluation reform. International Journal of Educational Management. doi:10.1108/IJEM-06-2017-0151

Mackey, K. H. (2016). The relationships among instructional leadership, School culture, and student achievement in Kentucky elementary schools.

Murphy, J. (1990). Principal instructional leadership. Advances in educational administration: Changing perspectives on the school, 1(Part B), 163-200.

Nettles, S. M., \& Herrington, C. (2007). Revisiting the importance of the direct effects of school leadership on student achievement: The implications for school improvement policy. Peabody Journal of Education, 82(4), 724-736.

Nixon, A., Packard, A., \& Dam, M. (2013). Principals judge teachers by their teaching. The Teacher Educator, 48(1), 58-72. doi:10.1080/08878730.2012.740154

Patton, M. Q. (2002). Two decades of developments in qualitative inquiry: A personal, experiential perspective. Qualitative social work, 1(3), 261-283. doi:10.1177/1473325002001003636

Rahiem, M. (2020). The emergency remote learning experience of university students in indonesia amidst the COVID-19 crisis. International Journal of Learning, Teaching and Educational Research, 19(6), 1-26. https://doi.org/10.26803/ijlter.19.6.1

Robinson, V. (2011). Student-centered leadership (Vol. 15): John Wiley \& Sons.

Saldaña, J. (2016). Ethnotheatre: Research from page to stage: Routledge.

Shaffer, J. A., DeGeest, D., \& Li, A. (2016). Tackling the problem of construct proliferation: A guide to assessing the discriminant validity of conceptually related constructs. Organizational Research Methods, 19(1), 80-110. doi:10.1177/1094428115598239

Shaked, H., Glanz, J., \& Gross, Z. (2018). Gender differences in instructional leadership: how male and female principals perform their instructional leadership role. School Leadership \& Management, 38(4), 417-434. doi:10.1080/13632434.2018.1427569

Silalahi, R., \& Yuwono, U. (2018). The sustainability of Pancasila in Indonesian education system. Research in Social Sciences and Technology, 3(2), 58-78.

Simmons, A. O. (2019). The Impact of Instructional Leadership on Student Reading Success. University of South Alabama, Retrieved from Retrieved from https:/ / search.proquest.com/docview /2212935716?accountid=27797

Sofo, F., Fitzgerald, R., \& Jawas, U. (2012). Instructional leadership in Indonesian school reform: overcoming the problems to move forward. School Leadership $\mathcal{E}$ Management, 32(5), 503-522. doi:10.1080/13632434.2012.723616

Southworth, G. (2005). Learning-centred leadership. The essentials of school leadership, 7592. doi:10.4135/9781446288290

Stronge, J. H., Ward, T. J., \& Grant, L. W. (2011). What makes good teachers good? A cross-case analysis of the connection between teacher effectiveness and student achievement. Journal of teacher Education, 62(4), 339-355. doi:10.1177/0022487111404241

Suratno, T. (2012). Lesson study in Indonesia: an Indonesia University of Education experience. International Journal for Lesson and Learning Studies. doi:10.1163/9789087907532_006 
Terosky, A. L. (2016). Enacting instructional leadership: perspectives and actions of public K-12 principals. School Leadership \& Management, 36(3), 311-332. doi:10.1080/13632434.2016.1247044

Vogel, L. R. (2018). Learning outside the classroom: How principals define and prepare to be instructional leaders. Education Research International, 2018. doi:10.1155/2018/8034270

Wright, L. L. (2010). Principal identity and educational change.

Yin, R. K. (2017). Case study research and applications: Design and methods: Sage publications.

Zepeda, S. J. (2014). The principal as instructional leader: A handbook for supervisors: Routledge.

Zhou, W., \& Li, G. (2015). Chinese language teachers' expectations and perceptions of American students' behavior: Exploring the nexus of cultural differences and classroom management. System, 49, 17-27. doi:10.1016/j.system.2014.10.011 